\title{
Evaluation of Safety Climate and its associated factors in Base Hospital
} Avissawella

DOI: $10.46981 /$ sfjhv2n2-006

Received in: April 1st, 2021

Accepted in: May 31th, 2021

\section{Munasinghage Priyanwada Jayalath}

Master of Sciences (Medical Administration) from Post Graduate Institute of Medicine University of Colombo

Institution: Ministry of Health, Nutrition \& Indigenous Medicine

Address: No 117/D, Koskolawattha, Pitumpe, Padukka, Sri Lanka

E-mail: priyanwadaj@gmail.com

\section{Samath Dhamminda Dharmaratne}

Doctor of Medicine (Community Medicine) from Post Graduate Institute of Medicine University of Colombo Sri Lanka

Institution: Department of Community Medicine, Faculty of Medicine, University of Peradeniya, Sri Lanka

Address: 71A Sri Dhammasiddhi Mawatha, Asgiriya, Kandy, Sri Lanka

E-mail: samath62@yahoo.com

\section{Dilantha Dharmagunawardene}

Doctor of Medicine (Medical Administration) from Post Graduate Institute of Medicine University of Colombo Sri Lanka

Institution: Ministry of Health, Nutrition \& Indigenous Medicine

Address: No. 45, Temple Road, Maharagama, Sri Lanka

E-mail : dilanthadharma@yahoo.co.uk

\begin{abstract}
The safety climate is "the summary of molar perceptions that employees share about their work environments" and associated with several factors. A descriptive cross-sectional study was done among a randomly selected sample of medical officers $(n=109)$ and nursing officers $(n=193)$ to evaluate the safety climate and its associated factors in Base Hospital Avissawella Sri Lanka. Among the six safety climate dimensions personal protective and engineering control equipment availability (mean=3.94, $\mathrm{SD}=0.67$ ) was perceived at the highest level. The lowest scored perceptual dimension was absence of job hindrances (mean=3.27, $\mathrm{SD}=0.83)$. Among the respondents $219(83.5 \%)$ had at least one exposure incident. There is no significant relationship between job category and workplace exposure incidents $(p=0.388)$. Only $28.3 \%(n=62)$ had reported about their injuries. Only $60.7 \%(n=159)$ were strictly compliant to safe work practices and the compliance of nursing officers was better than of medical officers $(\mathrm{p}=0.000)$. The safety climate had a negative association with workplace exposure incidents $(\mathrm{OR}<1.0)$ and a positive association with compliance to safe work practices. $(\mathrm{OR}>1.0)$. The respondents had negative perceptions about some of the safety climate dimensions. Workplace exposure incidents were common and the reporting behavior about injuries was poor among both categories of staff, but comparatively the nursing officers were better. Majority were "Strict compliant" to the safe work practices and compliance was better among nursing officers. Safety climate was negatively associated with exposure incidents and positively with the compliance. The hospital managers should pay more attention on safety of employees, provide adequate training opportunities on occupational safety and encourage employees' reporting behavior.
\end{abstract}


Key words: Safety climate, workplace exposure incidents, safe work practices

\section{INTRODUCTION}

The safety climate can be defined as "A summary of molar perceptions that employees share about their work environments"(Zohar, 1980:p.96). It can be described in 6 dimensions as (1)Management support for safety programs, (2)Absence of hindrances to safe work practices, (3)Availability of personal protective and engineering control equipment, (4)Minimal conflict and good communication among staff members, (5)Frequent feedback and training by supervisors and (6)Cleanliness and orderliness of the work site (Gershon et al., 2000). Employees' perceptions about safety are important because organizations with positive employee perceptions about safety report a low rate of injuries (Felknor et al., 2000).

This study was carried out to describe the safety climate within Base Hospital Avissawella , to describe the common types of workplace exposure incidents among selected health care workers, to describe the level of compliance with safe work practices and to analyze the association of safety climate with workplace exposure incidents and safe work practices.

\section{METHODOLOGY}

This study was a descriptive cross-sectional study and the total duration was 01 year. Data collection was done for a period of 01 month from April to May 2018. The Study population consisted of 132 Medical officers and 320 Nursing officers. The sample size was calculated using the online software named Rao soft ${ }^{\circledR}$ sample size calculator ("Sample Size Calculator by Raosoft, Inc.," n.d.). The actual sample size for the medical officers was 109 and the actual sample size for nursing officers was 193. Simple random sampling was used to select the sample from two groups in the study population. The study instrument was a self-administered questionnaire developed based on "20- item hospital safety climate scale" (Gershon et al., 2000). Face \& content validity was done with expert opinion. Pretesting of the questionnaire was done at Divisional Hospital Padukka. A 5-point Likert scale was used ranging from "Strongly Disagree / Never "(1) to "Strongly Agree / Always" (5) to assess the responses. Statistical analyses were completed using Microsoft Office Excel and Statistical Package for the Social Sciences (SPSS 21.0). Ethical approval was obtained from Ethical Review Committee Post Graduate Institute of Medicine Colombo. Administrative clearance was obtained from the relevant authorities. 


\section{RESULTS}

Table 1 The mean score for each safety climate dimension among respondents

\begin{tabular}{ll}
\hline Safety climate dimension(factor) & Mean (SD) \\
\hline Personal protective and engineering control equipment availability & $3.94(0.67)$ \\
Management support & $3.34(0.79)$ \\
Absence of job hindrances & $3.27(0.83)$ \\
Feedback /training & $3.35(0.71)$ \\
Cleanliness /orderliness & $3.35(0.86)$ \\
Minimal conflict / good communication & $3.67(0.76)$ \\
\hline
\end{tabular}

Among the six safety climate dimensions the respondents had placed personal protective and engineering control equipment availability (mean $=3.94, \mathrm{SD}=0.67)$ at the highest level according to their perception. The lowest scored perceptual dimension was absence of job hindrances (mean=3.27, $\mathrm{SD}=0.83)$. (Table 1)

Table 2 Comparison of workplace exposure incidents between two categories of staff

\begin{tabular}{lrrrrrrr}
\hline $\begin{array}{l}\text { Job } \\
\text { category }\end{array}$ & $\begin{array}{r}\text { Workplace exposure } \\
\text { incidents } \\
\text { Negative }\end{array}$ & $\begin{array}{r}\text { Workplace exposure } \\
\text { incidents } \\
\text { Positive } \\
\%\end{array}$ & No & No & $\%$ & Total \\
\hline $\begin{array}{l}\text { Medical } \\
\text { officer }\end{array}$ & 12 & 13.6 & 76 & 86.4 & 88 & 100 & $\begin{array}{c}\chi^{2}=0.744 \\
\text { degree of } \\
\text { freedom=1 }\end{array}$
\end{tabular}

$\begin{array}{llllllll}\begin{array}{l}\text { Nursing } \\ \text { officer }\end{array} & 31 & 17.8 & 143 & 82.2 & 174 & 100 & \begin{array}{r}\text { Significance }(2 \\ \text { tailed })=0.388\end{array}\end{array}$

\begin{tabular}{lllllll}
\hline Total & 43 & 16.4 & 219 & 83.6 & 262 & 100 \\
\hline
\end{tabular}

Level of significance $5 \%$

Out of 262 of the total respondents 219 (83.6\%) had had at least one exposure incident over the last six months. Out of the 88 medical officers 76 (86.4\%) and out of 174 nursing officers 143 (82.2\%) had at least one exposure incident over the last six months.

As the $\mathrm{p}$ value was 0.388 there was no significant relationship between job category and workplace exposure incidents. (Table 2)

Table 3 summarizes the reporting behavior of the respondents. Only $28.3 \%(n=62)$ respondents had reported about their injury to the relevant authorities. The reporting frequency was $18.4 \%(n=14)$ among the medical officers while it was $27.7 \%(n=48)$ among the nursing officers 
Table 3 Reporting behavior of respondents

\begin{tabular}{|c|c|c|c|c|c|c|}
\hline \multirow[t]{2}{*}{ Job category } & \multicolumn{2}{|c|}{$\begin{array}{l}\text { Respondents who } \\
\text { reported incidents }\end{array}$} & \multicolumn{2}{|c|}{$\begin{array}{l}\text { Respondents who } \\
\text { did not report incidents }\end{array}$} & \multicolumn{2}{|c|}{ Total } \\
\hline & No & $\%$ & No & $\%$ & No & $\%$ \\
\hline Medical officers & 14 & 18.4 & 62 & 81.6 & 76 & 100 \\
\hline Nursing officers & 48 & 27.7 & 125 & 72.3 & 173 & 100 \\
\hline Total & 62 & 28.3 & 157 & 71.7 & 219 & 100 \\
\hline
\end{tabular}

. Table 4 Comparison of "strict compliance" between two categories of staff

\begin{tabular}{|c|c|c|c|c|c|c|c|}
\hline \multirow[t]{2}{*}{ Job category } & \multicolumn{2}{|c|}{$\begin{array}{c}\text { Strict } \\
\text { Negative }\end{array}$} & \multicolumn{2}{|c|}{$\begin{array}{r}\text { compliance } \\
\text { Positive }\end{array}$} & \multicolumn{2}{|r|}{ Total } & \\
\hline & No & $\%$ & No & $\%$ & No & $\%$ & \\
\hline Medical officers & 56 & 63.6 & 32 & 36.4 & 88 & 100.0 & $\chi 2=32.859$ \\
\hline Nursing officers & 47 & 27.0 & 127 & 73.0 & 174 & 100.0 & $\begin{array}{r}\text { Degree of } \\
\text { freedom }=1\end{array}$ \\
\hline Total & 103 & 39.3 & 159 & 60.7 & 262 & 100.0 & $\begin{array}{r}\text { Significance }(2 \\
\text { tailed })=0.000\end{array}$ \\
\hline
\end{tabular}

Level of significance $=5 \%$

Only $36.4 \%(n=32)$ of the medical officers had "strict compliance" while $73 \%(n=127)$ of the nursing officers had "strict compliance". Among the total respondents 60.7\% $(n=159)$ were strictly compliant to safe work practices.

The $\mathrm{p}$ value was less than 0.05 and therefore there was a significant difference between the compliance among the two categories of job where compliance of nurses was better than doctors in their practices. (Table 4)

Table 5 Association of Safety Climate with Workplace Exposure Incidents

\begin{tabular}{lrr}
\hline Safety climate dimension & $\begin{array}{r}\text { Odds ratio } \\
\text { (OR) }\end{array}$ & $\begin{array}{r}95 \% \text { Confidence } \\
\text { interval }\end{array}$ \\
\hline Personal protective and engineering & & $0.303-0.984$ \\
control equipment availability & 0.546 & $0.331-0.849$ \\
Management support & 0.530 & $0.324-0.788$ \\
Absence of job hindrances & 0.505 & $0.194-0.678$ \\
Feedback/Training & 0.363 & $0.333-0.827$ \\
Cleanliness/Orderliness & 0.525 & \\
Minimal conflict/good communication & & $0.351-0.962$ \\
\hline
\end{tabular}

According to the table all six safety climate dimensions had a negative association with workplace exposure incidents. (Table 5) 
Table 6 Association of Safety Climate with Compliance to Safe Work Practices

\begin{tabular}{lrr}
\hline Safety climate dimension & $\begin{array}{r}\text { Odds ratio } \\
\text { (OR) }\end{array}$ & $\begin{array}{r}95 \% \text { Confidence } \\
\text { interval }\end{array}$ \\
\hline & & $1.293-2.901$ \\
Personal protective and engineering & & \\
control equipment availability & 1.940 & $1.535-3.047$ \\
Management support & 2.163 & $1.494-2.878$ \\
Absence of job hindrances & 2.074 & $2.085-4.831$ \\
Feedback/Training & 3.174 & $1.047-1.899$ \\
Cleanliness/Orderliness & 1.410 & $0.759-1.451$ \\
Minimal conflict/good communication & 1.049 & \\
\hline
\end{tabular}

According to the table all six safety climate dimensions were positively associated with safe work practices. Among them feedback/training $(\mathrm{OR}=3.174)$ and absence of job hindrances $(\mathrm{OR}=2.074)$ were highly associated with compliance to safe work practices. Minimal conflict /good communication $(\mathrm{OR}=1.049)$ was the least associated dimension with compliance to safe work practices. (Table 6)

\section{DISCUSSION}

In Sri Lanka the employees had given the highest mean score (3.94) to personal protective and engineering control equipment availability. It shows that they were satisfied with the availability of the necessary PPE in their institutions. The lowest score was given to absence of job hindrances (3.27). Being a secondary care hospital, it seems that work overload due to overcrowding (with a BOR of 95.9\% according to annual hospital data of 2017) had affected the employees to give the lowest score for that particular dimension of safety climate.

According to this study the mean scores for all safety climate dimensions had varied from 3.27 to 3.94. This was better than the overall mean score for safety climate items (2.84) in Costa Rica. It seems that although Sri Lanka spends only a limited amount of resources on health, for instance allocates only 3.5\% from GDP in 2014(WHO, 2018b) whereas Costa Rica spends 9.3\% from GDP(WHO, 2018a), we are more concerned about the safety of our employees when compared with Costa Rica.

Out of 262 of total respondents $219(83.5 \%)$ had had at least one exposure incident over the last six months. Out of the 88 medical officers 76 (86.4\%) and out of 174 nursing officers $143(82.2 \%)$ had at least one exposure incident. (Table 2). As the $\mathrm{p}$ value was 0.388 , there was no significant difference between job category and workplace exposure incidents at 5\% significance level. These results were different from the findings of the study done by Vithana et al at NHSL in which $68 \%$ of doctors and $38.23 \%$ of nurses had experienced at least one exposure. In Base Hospital Avissawella both categories were having high frequencies of injuries compared to NHSL, may be because more training opportunities on safety measures, adequate PPE and occupational safety guidelines were available in 
NHSL resulting less injuries. According to the study done by Mathan in Batticaloa district it was found that the prevalence of occupational injuries was $86.3 \%$ (Mathan, 2016). When this was compared with the corresponding value of this study $(83.6 \%, n=219)$ it did not show any significant difference as the $p$ value was 0.97606 at $5 \%$ significance level.

The reporting behaviour of workplace exposure incidents is summarized in table 3 and it was only $28.3 \%(n=62)$ which was not satisfactory. This was similar to the finding of the study done by Vithana "The reporting behavior of both groups was unsatisfactory and nurses were better .(Vithana et al., 2005).

It was found that in China (Liu et al., 2014) the HCWs followed an average of 5.3 of the 8 guidelines (66\%). In Avissawella only 60.7\% ( $\mathrm{n}=159)$ were strictly compliant to safe work practices (Table 4). This could be due to work overload, poor training, lack of guidelines and unavailability of PPE.

According to the table 5 all six safety climate dimensions had a negative association with workplace exposure incidents which means when the employees perceive that their safety climate is positive, they are less likely to meet with workplace exposure incidents.

Except for feedback/ training $(\mathrm{OR}=0.363)$ all other safety climate dimensions had an Odds ratio $>0.5$ with workplace exposure incidents explaining that when those safety climate dimensions are improved the incidence of workplace exposure incidents can be halved. This was a bit different from the finding in Gershon's study in which it was found that "the frequency of exposure incidents was significantly lower when senior managerial support was rated high and when employees reported safety feedback and when the training was good (Gershon et al., 2000).

The results were also slightly different from the finding of the study done by Cook. According to Cook "positive employee perceptions of safety climate are associated with lower occupational injury rates and those were significantly and inversely related to employee perception of supervisor participation and safety support climate which are two dimensions of hospital safety climate" (Cook et al., 2016).

This may be due to the difference in the study setting. This finding can be further explained by the finding in the study done by Priyangani regarding the associated factors of needle prick injuries among nursing officers in three general hospitals in Sri Lanka. It was found that only $2.8 \%$ of the respondents perceive that lack of knowledge is responsible for increased incidence of needle stick injuries (Priyangani, Dharmaratne, \& Sridharan, 2017). Likewise, it seems that the employees of Base Hospital Avissawella did not believe that feedback and training programs can reduce the incidence of occupational injuries. 
In the study done by Dejoy et al in USA, a similar result to this study, that safety climate perceptions contributed to reduced adverse events to nurses who handled antineoplastic drug was observed (Dejoy et al., 2017).

In the study done in Costa Rica also it was found that the results indicate a statistically significant and inverse relationship between safety climate and work injuries at a level of $p<0.0001$ : as safety climate improves, work injuries decline (Felknor et al., 2000).

The table 6 summarizes the association of safety climate dimensions with compliance to safe work practices. According to the table all six safety climate dimensions were positively associated with safe work practices. This means that when safety climate improves the employees' compliance to safe work practices also increases. Among all dimensions feedback/training ( $\mathrm{OR}=3.174)$, management support $(\mathrm{OR}=2.163)$ and absence of job hindrances $(\mathrm{OR}=2.074)$ were highly associated with compliance to safe work practices. This was almost in line with the finding of Gershon's study that "compliance was highly associated with senior managerial support and the absence of job hindrances"(Gershon et al., 2000).

This finding was also compatible with the findings of the study done in Costa Rica which revealed that there was a significant and positive association between the two variables at a level of $p<$ 0.0001: as safety climate improved, safety practices also improved (Felknor et al., 2000).

A very important finding in the local study was that employees perceived that if they were given more feedback and training opportunities on universal precautions their compliance would increase by 3 folds. $(\mathrm{OR}=3.174$ as in table 4.20). This may be due to the general perception that knowledge and training on standard precautions will increase the likelihood to adhere to them. This perception is supported by a significant number of studies related to the above mentioned subject .In a study done in Indonesia in 2007 it was revealed that there was a significant association between knowledge and perceived adherence to universal precautions with a p value $<0.001$ (Sari et al., 2011). In another study done in Pakistan in 2017 it was concluded that noncompliance to universal precautions is due to lack of awareness, inadequate and ineffective training(Arif et al., 2017). A study done by a post graduate trainee in MSc Medical Administration Patabendige has mentioned that training on standard precautions was significantly associated with a "good" level of practice on standard precautions (Patabendige, 2016). It seems that a considerable number of respondents in the study done in Avissawella were knowledgeable about this fact and based on this fact they had developed the above perception.

\section{LIMITATIONS}

This study was conducted in a single study setting, Base Hospital Avissawella. As a result, the findings cannot be generalized to other hospitals. 
The study was a cross sectional study and therefore there is a problem in determination of causality which means a person's compliance behavior can influence his perceptions on safety climate or vice versa. Likewise, it is difficult to determine the causal relationship between workplace exposure incidents and safety climate as well. A prospective study should be done to determine the causal relationship.

The study population consisted of only two categories of staff, medical officers and nursing officers. Therefore, the results cannot be generalized to other categories of HCWs.

"The 20-item hospital safety climate scale" developed by Gershon was designed to assess employee perception of management commitment towards only "bloodborne pathogen exposure management program". More comprehensive hospital safety climate scale should be used to evaluate overall safety programs of a hospital. (e.g. chemical management, infection control, radiologic management etc.)

The self-administered questionnaire might have led to provide incomplete responses. The effect of this on results was minimized by considering only the completed responses for analysis.

There will be a tendency to give socially desirable responses regarding compliance to safe work practices when a self-administered questionnaire is used. Passive observation for compliance to safe work practices was not used due to Hawthorne effect. If a combination of several data collection methods (triangulation) was used more precise responses could have been obtained. But due to time constraint this could not be done.

Similarly recall bias could have affected the information about workplace exposure incidents which might have led to underestimate or overestimate the injuries, to provide inaccurate information or to exaggerate the true situation.

\section{CONCLUSION}

Although Gershon's "The 20-item hospital safety climate scale" had been developed in USA this is a reliable measure of safety climate in Sri Lankan health care settings as well. Even though our health indicators are in pace with those of developed countries, we are still lagging in relation to the safety climate related to the occupational safety. Even though the employees perceived that they had an adequate supply of PPE and engineering control in their workplace (mean=3.94), they had relatively negative perceptions about absence of job hindrances to follow universal precautions(mean=3.27), management support on occupational safety(mean=3.34), feedback and training on occupational safety $($ mean=3.35) and cleanliness/ orderliness of the workplace $($ mean=3.35).

Workplace exposure incidents were common among the study population (83.6\%). There was no significant difference between the two categories of staff ( $\mathrm{p}$ value=0.388). The reporting behavior about 
the injuries to the relevant authorities was poor among both categories of staff $(28.3 \%)$, but comparatively the nursing officers were better.

The strict compliance to safe work practices was observed among $60.7 \%$ of the respondents. A significant difference between the compliance among the two categories was observed ( $p$ value $=0.000$ ) where compliance of nurses was better than doctors.

A negative association was observed between safety climate and workplace exposure incidents.

A positive association was observed between safety climate and compliance to safe work practices.

\section{RECOMMENDATIONS}

The perceptions of medical officers and nursing officers on hospital safety climate should be improved. Special attention should be paid on safety climate dimensions like absence of job hindrances, management support, feedback/training and cleanliness/ orderliness. The measures should be taken to minimize the negative effects of overcrowding/ work overload to follow universal precautions. The hospital management should encourage the employees to control crowd by introducing appointment systems, providing drugs for two months for clinic patients with less complications etc. The hospital managers should pay more attention on the safety of their employees. The employees should be provided with more training opportunities on occupational safety. Written guidelines on occupational safety should be made available in all the units of the hospital. The employees should be encouraged to implement quality and productivity concepts like 5S, Kaizen, JIT at their workplace.

The "20 item hospital safety climate scale" can be used periodically to evaluate the employee perceptions on safety climate. The required improvements can be made accordingly.

The medical officers and nursing officers should be encouraged to report the workplace exposure incidents to the relevant authorities.

The employees should be provided with adequate training opportunities on safe work practices. Periodic audits should be carried out to monitor the level of compliance to safe work practices. 


\section{REFERENCES}

1. Arif, A., Shah, S. I. ., Mumtaz, A., \& Chughatai, A. S. (2017). Knowledge, attitudes and practices of standard precautions among nursing professionals at a teaching hospital. Biomedica,33(4),314-319. Retrieved from https://www.researchgate.net/publication/326668561\%0A

2. Cook, J. M., Slade, M. D., Cantley, L. F., \& Sakr, C. J. (2016). Evaluation of safety climate and employee injury rates in healthcare. Occupational and Environmental Medicine, 73(9), 595-599.

Retrieved from https://doi.org/10.1136/oemed-2015-103218

3. Dejoy, D. M., Smith, T. D., Woldu, H., Dyal, M., Andrea, L., \& Boiano, J. M. (2017). Effects of Organizational Safety Practices and Perceived Safety Climate on PPE Usage, Engineering Controls, and Adverse Events involving Liquid Antineoplastic Drugs among Nurses. Journal of Occupational and Environmental Hygiene, 14(7), 485-493. Retireved from https://doi.org/10.1080/15459624.2017.1285496

4. Felknor, S. A., Aday, L. A., Burau, K. D., Delclos, G. L., \& Kapadia, A. S. (2000). Safety Climate and Its Association with Injuries and Safety Practices in Public Hospitals in Costa Rica. International Journal of Occupational and Environmental Health, 6(1), 18-25. Retrieved from https://doi.org/10.1179/oeh.2000.6.1.18

5. Gershon, R. R. M., Karkashian, C. D., Grosch, J. W., Murphy, L. R., Escamilla-Cejudo, A., Flanagan, P. A., Martin, L. (2000). Hospital safety climate and its relationship with safe work practices and workplace exposure incidents. American Journal of Infection Control, 28(3), 211-221.

Retrieved from https://doi.org/10.1067/mic.2000.105288

6. Liu, X., Sun, X., van Genugten, L., Shi, Y., Wang, Y., Niu, W., \& Richardus, J. H. (2014). Occupational exposure to blood and compliance with standard precautions among health care workers in Beijing, China. American Journal of Infection Control, 42(3), e37-e38. Retrieved from https://doi.org/10.1016/J.AJIC.2013.12.002

7. Mathan, F. P. (2016). OCCUPATIONAL HEALTH INJURIES AMONG HEALTH CARE WORKERS AT SECONDARY AND TERTIARY CARE HOSPITALS IN BATTICALOA DISTRICT.

8. $\quad$ Patabendige. (2016). Knowledge, Attitudes and Practices and the factors affecting the practices on standard precautions among nursing officers in selected Base Hospitals in the Southern Province of Sri Lanka.

9. Priyangani, Y. M. M., Dharmaratne, G. S. K., \& Sridharan, S. (2017). Factors Associated and Response to Needle Stick Injuries among Nursing Officers in District General Hospitals of Sri Lanka. Global Journal of Health Science, 9(8), 107.

Retrieved from https://doi.org/10.5539/gjhs.v9n8p107

10. Sample Size Calculator by Raosoft, Inc. (n.d.).

Retrieved October 27, 2018, from http://www.raosoft.com/samplesize.html

11. Sari, S. Y. I., Ibrahim, K., Haroen, H., Irvan, A., Sunjaya, D. K., Hinduan, Z. R., ... Meheus, A. (2011). Knowledge , attitude and perceived adherence with universal precautions among health care workers in the obstetrics and gynaecology department of an Indonesian teaching hospital. International Journal of Infection Control, 7i4(June), 1-7.

Retrieved from https://doi.org/10.3396/ijic.V7i4.036.11 
12. Vithana, V., Weerakkody, M., Pallewela, V., Karunanayake, P., Senarath, U., \& Sheriff, M. (2005). Management of occupational exposure to blood and body fluids among health care workers in the National Hospital of Sri Lanka :an audit of practice; In Sri Lanka Medical Association - 118th Anniversary Academic Sessions (p. 50).

13. WHO. (2018a). WHO | Costa Rica. Retrieved October 27, 2018 from http://www.who.int/countries/cri/en/

14. WHO. (2018b). WHO | Sri Lanka. Retrieved October 27, 2018, from http://www.who.int/countries/lka/en/

15. Zohar, D. (1980). Safety climate in industrial organizations: Theoretical and applied implications. Journal of Applied Psychology, 65(1), 96-102.

Retrieved from https://doi.org/10.1037/0021-9010.65.1.96 